\title{
Seção temática: Gênero e políticas públicas Análise de arranjos de implementação de políticas públicas de enfrentamento à violência contra mulheres em municípios de pequeno porte
}

\author{
Ana Carolina Almeida Santos Nunes
}

Universidade Federal do $A B C$ (UFABC)

A implementação de políticas públicas de enfrentamento à violência contra mulheres apresenta um grande desafio no âmbito de municípios de pequeno porte, realidade pouco explorada por pesquisas. O presente trabalho analisa os arranjos de implementação dessas políticas em Afogados da Ingazeira - PE e Palmeira das Missões - RS, partindo das premissas estabelecidas pela Lei Maria da Penha e pelo Pacto Nacional pelo Enfrentamento à Violência Contra as Mulheres. Por meio de uma adaptação das abordagens de análise dos arranjos institucionais e de modelos de coprodução de políticas públicas, estabeleceu-se quatro dimensões para a análise desses arranjos: (a) articulação intersetorial, (b) articulação e colaboração entre os diferentes entes federativos, (c) tratamento dado à dimensão territorial e (d) modelos de coprodução de políticas públicas. Os achados da pesquisa trazem elementos importantes para a discussão da adaptação do desenho institucional de políticas nacionais para realidades locais.

Palavras-chave: políticas públicas, mulher, violência contra a mulher, administração municipal

[Artigo recebido em 15 de julho de 2017. Aprovado em 23 de agosto de 2017.] 
Análisis de arreglos de implementación de políticas públicas de combate a la violencia contra mujeres en municipios pequeños

La implementación de políticas públicas de combate a la violencia contra las mujeres presenta un gran reto en el contexto de municipios pequeños, una realidad poco explorada en investigaciones. En el presente trabajo se analizan los arreglos de implementación de esas políticas en Afogados da Ingazeira - PE y en Palmeira das Missões - RS, partiendo desde las premisas establecidas por la Ley Maria da Penha y por el Pacto Nacional por el Combate a la Violencia Contra las Mujeres. Por medio de una adaptación de los abordajes de análisis de los arreglos institucionales y de modelos de coproducción de políticas públicas, fueron establecidas cuatro dimensiones para el análisis de esos arreglos: (a) articulación intersectorial, (b) articulación y colaboración entre las diferentes entidades federales, (c) tratamiento de la dimensión territorial y (d) modelos de coproducción de políticas públicas. Los hallazgos de la investigación traen elementos importantes para la discusión acerca de la adaptación del diseño institucional de políticas nacionales a las realidades locales.

Palabras clave: políticas públicas, mujer, violencia contra la mujer, administración municipal

\section{Analysis of implementation arrangements of public policies to address violence against} women in small municipalities

The implementation of public policies to address violence against women faces a big challenge in the reality of small municipalities. This work analyses the implementation arrangements of these policies in Afogados da Ingazeira - PE and Palmeira das Missões - RS, starting from the premises determined by Maria da Penha Law and the National Pact for Combating of Violence Against Women. Through an adaptation of the analytical approaches of institutional arrangements and public policies co-production models, four dimensions were determined for the analysis of the arrangements: (a) intersectoral articulation, (b) articulation and collaboration among distinct federal entities, (c) comprehension of the territorial dimension and (d) models of public policies coproduction. The findings of the investigation point out to important elements of the discussion about the institutional design adaptation of national policies to local realities.

Keywords: public policy, women, violence against women, municipal administration 


\section{Introdução}

A implementação de políticas públicas é um tópico que ganha força nas agendas de pesquisa conforme emerge a atenção sobre o desempenho do Estado. Inicialmente lida como uma etapa adjacente nos processos das políticas públicas (BARRETT, 2004), a partir de trabalhos como o de Pressman e Wildavsky (1984), entendeu-se que a implementação é um processo em si mesmo, na qual as ideias concebidas na formulação seguem sendo interpretadas e traduzidas.

As políticas públicas de gênero ${ }^{1}$, por sua vez, vêm se destacando enquanto temática de investigação não somente pelos avanços políticos observados nas últimas décadas, mas também pela urgência das questões que buscam resolver. Esse destaque se deve principalmente ao amplo esforço do movimento de mulheres brasileiro em levantar essa pauta na agenda pública (PINTO, 1994; SOARES, 1994), e à recente institucionalização das políticas públicas para mulheres ${ }^{2}$, que se materializa na criação da Secretaria de Políticas para Mulheres (SPM) com status de ministério e na promulgação da Lei Maria da Penha (PITANGUY, 2003; CALAZÁNS; CORTÉs, 2011).

Onze anos após a promulgação dessa Lei, que é considerada uma das três melhores legislações do mundo pela ONU e é conhecida por $97 \%$ da população brasileira ${ }^{3}$, segue na agenda pública o debate sobre como efetivar a sua aplicação. As políticas públicas de enfrentamento à violência contra mulheres são iniciativas fundamentais para que a legislação se cumpra e, segundo a previsão normativa, sua implementação deve envolver todas as esferas de governo e atores nãogovernamentais. $\mathrm{O}$ acesso pleno a direitos pelas mulheres depende, portanto, da colaboração e do trabalho articulado entre todos os entes federativos, os Três Poderes e a sociedade civil.

Neste sentido, o Pacto Nacional pelo Enfrentamento à Violência Contra as Mulheres (PNEVCM) apresenta-se como uma iniciativa que busca capilarizar e potencializar as ações do poder público a partir de uma visão integral do problema

\footnotetext{
${ }^{1}$ Considere-se a seguinte definição Considere-se a seguinte definição de para políticas públicas e gênero: iniciativas que consideram as diferenças nos processos de socialização entre homens e mulheres e nas suas consequências nas vivências individuais e coletivas de homens e mulheres, e se propõem a enfrentar e desconstruir as desigualdades geradas por esses processos (SOARES, 2004).

2 Entende-se aqui que as políticas públicas para mulheres compõem as políticas públicas de gênero, mas com um horizonte mais reduzido. Conforme destaca Bandeira (2005, p.9): “As políticas para as mulheres não são excludentes das políticas de gênero, embora tenham uma perspectiva restrita, pontual, de menor abrangência, atendendo a demandas das mulheres, mas sem instaurar uma possibilidade de ruptura com as visões tradicionais do feminino".

${ }^{3}$ Informações divulgadas pelo Portal Brasil no link http://www.brasil.gov.br/cidadania-e-justica/2015/10/9-fatosque-voce-precisa-saber-sobre-a-lei-maria-da-penha (último acesso em julho de 2017)
} 
(CARDOSO, 2009) e articulação entre os diversos atores e atrizes. O Pacto tem como premissas a transversalidade, intersetorialidade e a capilaridade (BRASIL, 2010).

Quando se observa o contexto de implementação das políticas públicas de enfrentamento à violência contra mulheres, é possível reconhecer que as desigualdades regionais, sociais, raciais e étnicas, entre outras, impõem grandes desafios ao poder público. A violência de gênero é uma problema pandêmico enraizado na sociedade brasileira e presente em todo o território, mas atinge a diversidade de mulheres de maneiras distintas de acordo com sua realidade. Nesse sentido, especialistas no tema destacam a importância de as políticas de enfrentamento a esse problema serem adaptadas às realidades locais e desenvolvidas em conjunto com as próprias mulheres (PRADO; SANEMATSU, 2017).

Para garantir o acesso universal a direitos observando as diferentes realidades, é essencial a colaboração entre governo central e governos subnacionais, especialmente municípios. De acordo com a própria SPM (BRASIL, 2011), as ações de competência municipal no âmbito das políticas públicas de enfrentamento à violência contra mulheres são a criação/reaparelhamento de serviços especializados, como centros de referência e casas-abrigo, e a realização de campanhas locais. O PNEVCM, por sua vez, prevê as seguintes responsabilidades aos governos municipais:

a. Prestar contas, junto à SPM e demais Ministérios envolvidos, dos convênios firmados pelas instituições municipais; b. Garantir a sustentabilidade dos projetos; c. Participar da Câmara Técnica de Gestão Estadual; d. Promover a constituição e o fortalecimento da rede de atendimento à mulher em situação de violência, no âmbito municipal e/ou regional, por meio de consórcios públicos (quando couber); [...] (BRASIL, 2010)

Tendo em vista a importância dos municípios na efetivação da Lei Maria da Penha e na implementação de políticas públicas de enfrentamento à violência contra mulheres e os desafios imbricados nesse processo, o presente artigo se propõe a analisar como se dá essa implementação no contexto de municípios de pequeno porte, um universo pouco discutido pelas literaturas de estudos de implementação e de políticas de gênero. A escolha desse recorte se justifica também nos dados alarmantes de que $72,3 \%$ dos municípios brasileiros registraram homicídios de mulheres em 2013 (WAISENFILZ, 2015) e de que as maiores taxas de assassinatos com motivação de gênero estão nos municípios de menos de 50 mil habitantes (PRAdo; SANEMATSU, 2017). A demanda por interiorizar essas políticas públicas e adaptá-las aos diversos contextos é, portanto, urgente (MARTINS; CERQUEIRA; Matos, 2015; PRAdo; SANematsu, 2017). 
São analisados os arranjos de implementação de políticas públicas de enfrentamento à violência contra mulheres em dois municípios de pequeno porteAfogados da Ingazeira - PE e Palmeira das Missões - RS -, de modo a compreender como os desenhos institucionais se adaptam às realidades e dinâmicas locais. $A$ análise busca abranger o campo de forças, normas e instituições que constituem o microcosmos da implementação de uma política pública complexa. Os parâmetros da análise partem do modelo de governança do PNEVCM, que destaca a necessidade das articulações horizontal e vertical entre os atores, a participação de atores nãogovernamentais e a adaptação das ações aos contextos territoriais. Esses eixos, por sua vez, compõem as quatro dimensões da análise, adaptadas da proposta de análise dos arranjos institucionais de Lotta e Favareto (2016). Dessa forma, os resultados podem contribuir para a discussão posterior dos modelos de governança do Pacto Nacional.

\section{Abordagens de análise dos arranjos institucionais e coprodução de políticas públicas}

O processo de implementação é visto como um contínuo, dentro do qual a política pública ganha novos formatos e conformações (HUPE e HILL, 2002; FARIA, 2003). Os estudos de implementação, por sua vez, podem gerar subsídios para solucionar as diferenças de conformidade entre o que é implementado e o que foi formulado, ou podem se propor a compreender como se dão essas mudanças nas diferentes realidades nas quais as políticas públicas são produzidas e quais os seus impactos sobre as entregas.

A pesquisa aqui apresentada se enquadra na segunda proposta, buscando uma abordagem metodológica multidisciplinar nos estudos de implementação. De acordo com Barrett (2004), busca-se articular, por um lado, as necessidades em manter alguns parâmetros de qualidade de implementação das políticas públicas, e por outro, a realidade dos processos de implementação que se observa empiricamente. O intuito da investigação, portanto, não é avaliar as políticas públicas, mas compreender como seus arranjos de implementação se apresentam na prática e como influenciam os resultados das mesmas.

Para a investigação, usam-se as abordagens de análise dos arranjos institucionais e de coprodução, adaptadas à pergunta de pesquisa. Ambas permitem agregar novas variáveis na análise do processo de implementação para além da comparação entre a proposta da política pública e a sua entrega -, valorizando a compreensão das interações entre atores. 
É importante destacar que, com a redemocratização, lançam-se novos contornos institucionais que alteram completamente a forma de produção de políticas públicas e impõem novos requisitos à ação do Estado, como o (re)arranjo federativo, a instituição de dispositivos de participação e a ampliação da capacidade da burocracia (ARRetche, 2002; BICHIR, 2011; PIRES; GoMIde, 2014; BRESSER-PEREIRA, 1998). Some-se a isso a especialização cada vez maior das políticas públicas, forçada pela evolução do debate, pelas demandas constitucionais e pela própria pressão de movimentos organizados.

Uma vez que se busca abarcar a complexificação do processo de produção de políticas, propõe-se analisar seus arranjos institucionais, que definem de que maneira os processos são coordenados e quais são as atribuições dos diferentes atores (LOTTA; VAZ, 2015; PIRES; GOMIDE, 2014; LOTTA; FAVARETO, 2016). A compreensão do conceito mais utilizada pelas análises atuais na agenda brasileira, da qual este trabalho compartilha, é definida por Pires e Gomide (2012, p.14): "Por arranjos institucionais entende-se o conjunto de regras, organizações e processos que definem a forma como se coordenam os atores e os interesses em pauta em uma determinada política pública".

Lotta e Favareto (2016) propõem uma matriz de comparação dos arranjos institucionais de diferentes políticas a partir de quatro dimensões:

- $\quad$ articulação entre setores de políticas públicas (integração horizontal): como os diferentes setores se articulam para construir soluções conjuntas (CUNILL GRAU, 2005; INOJOSA, 1998).

- modelos de coordenação e cooperação entre entes federativos (integração vertical): relações entre entes, analisando quais são as responsabilidades e relações na produção das políticas públicas, especialmente as formas de indução, coordenação e controle dos níveis mais altos em direção aos entes relacionados abaixo.

- tratamento da dimensão territorial: entender se ela é incorporada por instrumentos de planejamento e gestão e se as forças sociais da heterogeneidade dos territórios são incentivadas a participar dos processos da política pública (LOTTA; FAVARETo, 2016).

- participação: analisar os mecanismos institucionais de participação, transparência e prestação de contas com atores sociais, sejam eles o público beneficiário ou impactado, a sociedade civil organizada ou entes privados.

Outra mudança desde a redemocratização que teve impacto na forma de se fazer as políticas públicas foi a abertura cada vez maior aos atores externos ao Estado ou ao órgão implementador para participarem diretamente da produção dos serviços 
públicos. No âmbito das políticas sociais, por exemplo, destaca-se a possibilidade de contratação de organizações públicas não estatais, que levantou novas demandas de coordenação por parte dos contratantes. Já a própria especialização das políticas públicas tem levado cada vez mais governos locais a recorrer a parcerias com outros governos, poderes ou organizações não estatais para conseguir formular e implementar de acordo com as demandas.

A coprodução de políticas públicas é um conceito emergente na agenda de estudos de políticas públicas, que aqui definimos como a participação de outros atores, que não a organização provedora, na produção de serviços públicos e políticas públicas (OSTROM, 1996). Isso inclui desde a parceria com entes privados e conveniamentos até a participação de cidadãs e cidadãos de forma institucionalizada (HUPE, 1993) ou não (TOPS, 1999). Hupe e Hill (2002, p.135) resumem a definição de coprodução como uma abordagem na qual um governo nacional ou local envolve cidadãos, organizações sem fins lucrativos, empresas ou outros governos na produção de uma política pública específica.

No âmbito da implementação de políticas nacionais em municípios, a análise das formas de coprodução permite identificar a rede envolvida na execução das políticas, o que contribui para compreender suas potencialidades e a influência dessas parcerias nos resultados.

\section{Metodologia}

A pesquisa de campo foi realizada no ano de 2017, nos municípios de Afogados de Ingazeira - PE e Palmeira das Missões - RS, além das capitais de cada estado. Foram entrevistadas gestoras e gestores públicos de todas as áreas envolvidas nas políticas públicas de enfrentamento à violência contra mulheres, em seus respectivos locais de trabalho, além de representantes da sociedade civil e burocratas do nível de rua, totalizando 49 entrevistas semiestruturadas.

Os municípios foram escolhidos com base em 5 critérios: (1) ter menos de 50 mil habitantes, (2) ter um Organismo Municipal de Políticas para Mulheres (OPM), (3) ter um Conselho Municipal dos Direitos da Mulher, (4) ser indicado como referência em implementação de políticas públicas de combate à violência contra mulheres, (5) não fazer parte de região metropolitana. Inicialmente, as referências enunciadas pelo critério (4) foram buscadas entre gestoras da SPM do governo federal. Diante da dificuldade em obter essas referências, optou-se por direcionar a pesquisa a dois estados que se destacam por ter muitos municípios que implementaram políticas públicas para mulheres: Pernambuco e Rio Grande 
do Sul. As pessoas entrevistadas nas capitais indicaram municípios de referência nos seus estados, o que conduziu a pesquisa à imersão nos municípios indicados. A seleção de entrevistados se deu por meio da técnica bola de neve, partindo das gestoras municipais e estaduais dos OPMs.

Em consonância com a proposta de imersão no campo-tema, as conversas informais, os espaços de trabalho e os discursos escritos e não-escritos compunham a observação (BATISTA; BernaRdes; MEnEgon, 2014; CoRdeiro; BRASILINo; CARdonA, 2014). Ao longo da pesquisa de campo, foram construídas sequências narrativas sobre a implementação das políticas públicas de enfrentamento à violência contra mulheres nos dois municípios estudados.

Foram consideradas na análise três das quatro dimensões da abordagem propostas por Lotta e Favareto (2016): a integração horizontal (articulação intersetorial); a integração vertical (articulação e colaboração entre os diferentes entes federativos); e como é tratada a dimensão territorial. A quarta dimensão da proposta dos autores é a de participação, que, para a presente pesquisa, foi alterada para modelos de coprodução de políticas públicas.

A intersetorialidade e a integração vertical são princípios contidos no próprio conteúdo da política pública analisada, o que aponta um campo fértil para a análise dessas dimensões. Assim como a dimensão da coprodução, uma vez que a colaboração e a participação ativa de cidadãos, individual ou coletivamente, estão apontadas no escopo da política pública estudada. A pesquisa, então, visa compreender quem são seus coprodutores (redes e parcerias intra e intergovernamentais) no âmbito dos municípios e quais são os modelos de coprodução existentes. Por fim, considerando que a capilaridade também é uma premissa da política pública analisada, a dimensão territorial se mostra essencial para o entendimento da sua adaptação aos contextos locais.

As entrevistas e o levantamento de dados foram conduzidos de modo a responder às perguntas do quadro de referência de análise de arranjos institucionais, que tem norteado as pesquisas de Lotta e Favareto (2016). 
Tabela 1 - Dimensões de análise dos arranjos de implementação

\begin{tabular}{|c|c|c|c|}
\hline $\begin{array}{l}\text { Integração } \\
\text { horizontal } \\
\text { (intersetorialidade) }\end{array}$ & $\begin{array}{l}\text { Integração vertical } \\
\text { (subsidiariedade } \\
\text { federativa) }\end{array}$ & $\begin{array}{l}\text { Coprodução de } \\
\text { serviços públicos }\end{array}$ & $\begin{array}{l}\text { Dimensão } \\
\text { territorial }\end{array}$ \\
\hline $\begin{array}{l}\text { Há intersetorialidade } \\
\text { na formulação } \\
\text { da política? } \\
\text { (ex: sistemas e } \\
\text { instrumentos de } \\
\text { diagnóstico ou } \\
\text { planejamento } \\
\text { interministeriais) }\end{array}$ & $\begin{array}{l}\text { Quem faz as } \\
\text { regras da política } \\
\text { efetivamente? } \\
\text { (governo federal, } \\
\text { estadual ou } \\
\text { municipal?) } \\
\text { O que se prevê no } \\
\text { pacto federativo } \\
\text { em termos de } \\
\text { competências } \\
\text { constitucionais } \\
\text { neste tema/setor? }\end{array}$ & $\begin{array}{l}\text { Que atores } \\
\text { participam da } \\
\text { formulação } \\
\text { da política? } \\
\text { (descrever atores } \\
\text { da sociedade, } \\
\text { do estado ou } \\
\text { do mercado e } \\
\text { que arranjo de } \\
\text { participação } \\
\text { há - conselhos, } \\
\text { conferências, } \\
\text { audiências } \\
\text { públicas, GTs, } \\
\text { fóruns etc.) }\end{array}$ & $\begin{array}{l}\text { Como a política } \\
\text { lida com a } \\
\text { dimensão } \\
\text { territorial? (há } \\
\text { menções a } \\
\text { especificidades } \\
\text { espaciais ou à } \\
\text { necessidade } \\
\text { de diferenciar/ } \\
\text { adaptar os } \\
\text { instrumentos } \\
\text { de políticas a } \\
\text { contextos es- } \\
\text { pecíficos (como } \\
\text { diagnósticos } \\
\text { locais)? }\end{array}$ \\
\hline $\begin{array}{l}\text { Há intersetorialidade } \\
\text { na implementação } \\
\text { da política? (ex: } \\
\text { execução feita } \\
\text { em conjunto } \\
\text { entre diferentes } \\
\text { ministérios) }\end{array}$ & $\begin{array}{l}\text { Quem financia a } \\
\text { política? (governo } \\
\text { federal, estadual } \\
\text { ou municipal?) E } \\
\text { qual instrumento } \\
\text { de financiamento } \\
\text { (convênio, origem } \\
\text { dos recursos - } \\
\text { Tesouro, Fundo } \\
\text { etc.) }\end{array}$ & $\begin{array}{l}\text { Que atores } \\
\text { participam da } \\
\text { implementação } \\
\text { da política? } \\
\text { (descrever atores } \\
\text { da sociedade, } \\
\text { do estado ou } \\
\text { do mercado e } \\
\text { que arranjo de } \\
\text { participação } \\
\text { há - conselhos, } \\
\text { conferências, } \\
\text { audiências } \\
\text { públicas, GTs, } \\
\text { fóruns etc.) }\end{array}$ & $\begin{array}{l}\text { Há espaços de } \\
\text { participação } \\
\text { territoriais } \\
\text { (fóruns, } \\
\text { conselhos, } \\
\text { comitês, } \\
\text { colegiados) } \\
\text { previstos? }\end{array}$ \\
\hline $\begin{array}{l}\text { Há intersetorialidade } \\
\text { no monitoramento e } \\
\text { avaliação da política? } \\
\text { (ex: sistemas } \\
\text { integrados, grupos } \\
\text { de trabalho, comitês } \\
\text { gestores, salas de } \\
\text { situação etc.) }\end{array}$ & $\begin{array}{l}\text { Quem implementa } \\
\text { a política? } \\
\text { (governo federal, } \\
\text { estadual ou } \\
\text { municipal?) }\end{array}$ & $\begin{array}{l}\text { Que atores } \\
\text { participam } \\
\text { da avaliação } \\
\text { da política? } \\
\text { (descrever atores } \\
\text { da sociedade, } \\
\text { do estado ou } \\
\text { do mercado e } \\
\text { que arranjo de } \\
\text { participação há) }\end{array}$ & $\begin{array}{l}\text { Há formas de } \\
\text { articulação/ } \\
\text { diálogo/ } \\
\text { integração } \\
\text { com outras } \\
\text { instâncias } \\
\text { participativas já } \\
\text { existentes nos } \\
\text { territórios? }\end{array}$ \\
\hline
\end{tabular}

Elaboração: Lotta e Favareto (2016). 


\section{Desigualdades na efetivação da Lei Maria da Penha}

O movimento de mulheres no Brasil é marcado pela diversidade e heterogeneidade (SOARES, 1994), reunindo não só o movimento feminista, mas também mulheres ligadas a partidos, sindicatos, movimentos sociais rurais e urbanos. As reivindicações, historicamente, variaram desde a democratização dos espaços de poder público e privado, direitos sociais até o combate à precarização da qualidade de vida. No entanto, os diversos movimentos que o compõem unem forças quando a pauta é o enfrentamento à violência e o combate à discriminação de gênero (PItAnguY, 2002; PrÁ, 2012; MACDOWELl SANTOS, 2010).

Uma das principais conquistas das mulheres mobilizadas foi a criação da Lei Maria da Penha, que se desdobrou na inclusão de políticas públicas para mulheres no orçamento federal (BANDEIRA, 2005). No entanto, é possível identificar discrepâncias gritantes no enfrentamento da violência contra mulheres, por exemplo, nas variações entre evoluções positivas e negativas nas taxas de homicídios de mulheres de estado para estado. O Mapa Nacional da Violência de 2015 (WAISENFILZ, 2015) mostra que a taxa de homicídios de mulheres por 100 mil habitantes aumentou 12,5\% no Brasil entre 2006 e 2103. Enquanto em estados como Pernambuco, São Paulo e Rio de Janeiro foram registrados mais de $20 \%$ de queda, Roraima registrou o impressionante aumento de $131 \%$ da mesma taxa.

Outro reflexo dessas discrepâncias é o aumento em 19,5\% de vitimização de mulheres negras por feminicídios, segundo o Mapa da Violência 2015, entre 2003 e 2013. No mesmo período, a taxa de vitimização de mulheres brancas caiu $11,9 \%$. Na avaliação de ativistas feministas, urge uma abordagem interseccional da violência contra mulheres negras e indígenas, uma vez que as respostas até agora adotadas não têm se mostrado suficientes para reduzir a violência contra esses grupos específicos (Prado; SANematsu, 2017; CARneiro, 2017).

Os dados sobre homicídios de mulheres apontam quando há falha na proteção do Estado para mulheres em situação de violência. As discrepâncias nesse indicador são uma evidência de que as políticas públicas até agora implementadas não conseguiram impactar todas as mulheres brasileiras na mesma intensidade. Seja por questões territoriais, de gestão ou desigualdades de renda e raça, o que se observa é que a Política Nacional de Enfrentamento à Violência Contra as Mulheres, ainda recente, está distante do seu objetivo de garantir proteção integral à integridade de todas as cidadãs, especialmente aquelas inseridas em contextos de vulnerabilidade.

A trajetória do movimento de mulheres brasileiro aponta para a necessidade de se contemplar a diversidade de identidades e contextos sociais nas políticas 
públicas para mulheres (SOARES, 1994; FARAH, 2002). Os direitos sociais e a interseccionalidade da desigualdade de gênero com as desigualdades sociais, de raça e por orientação sexual marcam a agenda desse movimento, que foi absorvida pelas diretrizes de políticas públicas de para mulheres no Brasil. Em relação ao enfrentamento à violência contra mulheres não poderia ser diferente, como fica provado pelo conteúdo da Lei Maria da Penha e do PNEVCM. Ambos determinam que a atuação do Estado, no que tange à temática, deve ser adaptada às realidades locais e à multiplicidade de sujeitos e territórios, sob pena de ampliar as desigualdades.

A partir dos casos apresentados e analisados em seguida, é possível refletir sobre como o desenho institucional das políticas públicas de enfrentamento à violência contra mulheres pode ser adaptado de modo a superar essas desigualdades.

\section{Pernambuco e Afogados da Ingazeira}

Conforme o que foi constatado na pesquisa de campo em janeiro de 2017, o governo estadual do Pernambuco conta com um OPM bem estruturado e com altas capacidades de coordenação e execução. As políticas públicas de enfrentamento à violência são integradas às políticas de geração de renda e promoção da cidadania. O organismo tem uma agenda forte de capilarização das políticas públicas para mulheres e conta com coordenadoras de cada macrorregião do estado para acompanhar as agendas locais. O estado também oferece um mecanismo próprio de financiamento de políticas para mulheres em municípios e se responsabiliza pela gestão dos equipamentos de abrigamento de mulheres em situação de violência.

Em Afogados da Ingazeira, o OPM é coordenado por uma gestora com alta capacidade técnica e de articulação e a agenda de gênero tem apoio dentro da gestão municipal. A sociedade civil participa ativamente na formulação e implementação das políticas públicas e respalda a atuação da coordenadora do OPM. Os gestores da Prefeitura dispõem de mecanismos de articulação intersetorial e a agenda de políticas públicas para mulheres é adaptada às particularidades do território. Por fim, o OPM estadual apoia o município na elaboração e implementação dessas políticas públicas, que também conta com a cooperação do Sistema de Justiça.

\section{Rio Grande do Sul e Palmeira das Missões}

O governo estadual do Rio Grande do Sul vem desmontando suas estruturas de execução de políticas públicas para mulheres, o que se reflete em menos recursos para as prefeituras. Na gestão anterior, no entanto, havia uma agenda de 
fortalecimento da Rede Lilás, composta pelos equipamentos de atendimento às mulheres. O governo do estado fornecia veículos (viabilizados por convênio com o governo federal) aos municípios para ajudar a estruturar essa rede, mas não chegava a acompanhar a evolução territorializada das políticas públicas. Uma inovação promovida pelo OPM do governo estadual, ainda na gestão anterior, é a alocação da assessoria técnica a municípios no equipamento estadual de atendimento, que normalmente presta serviços apenas ao público geral. Outro destaque é o fato de os municípios serem incentivados a constituir consórcios para gerir equipamentos de abrigamento a mulheres em situação de violência.

Em Palmeira das Missões - RS, a implementação de ações de enfrentamento à violência contra mulheres está mais a cargo de uma rede informal formada por atores do Poder Judiciário, da Polícia Civil e da burocracia de nível de rua da Assistência Social. A gestora do OPM municipal, por sua vez, tem pouco conhecimento sobre as ações em curso e não promove a articulação dos atores envolvidos na temática de gênero. O Conselho Municipal de Direitos da Mulher e as organizações da sociedade civil ligadas à temática de gênero atuam pautando o tema na agenda municipal e promovendo atividades pontuais com o apoio da Prefeitura, mas as suas funções se misturam com a do OPM, que parece não ter atuação definida. Enquanto isso, o governo estadual apoia pouco o município na implementação de políticas públicas para mulheres.

\section{Análises e reflexões sobre os casos}

Ambos municípios estão na faixa de 30 mil habitantes, situados a mais de 300 quilômetros das capitais de seus estados, cujos OPMs e Conselhos Municipais de Direitos Mulher foram instalados há menos de 3 anos e cujos prefeitos foram reeleitos. Ainda que não estivesse previsto no desenho metodológico, os dois casos pesquisados se complementam por representarem situações opostas, apesar das similaridades.

Entretanto, as políticas públicas de enfrentamento à violência contra mulheres por eles implementadas estão em estágios muito distintos. Em Afogados da Ingazeira - PE há políticas públicas sendo implementadas e notória evolução na organização das ações de enfrentamento à violência contra mulheres desde a criação do OPM. Já em Palmeira das Missões - RS verifica-se uma atuação muito tímida do OPM, que se reflete na ausência de políticas públicas estruturadas e na desarticulação da rede de atendimento a mulheres em situação de violência.

Na Tabela 2, é possível comparar as avaliações dos dois casos a partir das quatro dimensões de análise estabelecidas pela pesquisa: 
Tabela 2 - Análise dos arranjos de implementação nos municípios

\begin{tabular}{|c|c|c|c|c|}
\hline & $\begin{array}{l}\text { Integração } \\
\text { horizontal } \\
\text { (intersetorial) }\end{array}$ & $\begin{array}{l}\text { Integração } \\
\text { vertical } \\
\text { (entre entes } \\
\text { federativos) }\end{array}$ & $\begin{array}{l}\text { Coprodução } \\
\text { de políticas } \\
\text { públicas }\end{array}$ & $\begin{array}{l}\text { Dimensão } \\
\text { territorial }\end{array}$ \\
\hline $\begin{array}{l}\text { Afogados } \\
\text { da } \\
\text { Ingazeira } \\
\text { - PE }\end{array}$ & $\begin{array}{l}\text { Alta. O OPM } \\
\text { se relaciona } \\
\text { com todas as } \\
\text { secretarias } \\
\text { que têm } \\
\text { mulheres } \\
\text { dentre os } \\
\text { alvos de suas } \\
\text { políticas } \\
\text { públicas, além } \\
\text { de se articular } \\
\text { com a Justiça. }\end{array}$ & $\begin{array}{l}\text { Média. } \\
\text { Cooperação } \\
\text { direta com } \\
\text { governo } \\
\text { estadual, } \\
\text { que cria } \\
\text { mecanismos } \\
\text { para facilitar a } \\
\text { implementação } \\
\text { em municípios. } \\
\text { Não há } \\
\text { contato direto } \\
\text { com a SPM } \\
\text { do governo } \\
\text { federal. }\end{array}$ & $\begin{array}{l}\text { Participação } \\
\text { direta de } \\
\text { movimentos } \\
\text { de mulheres na } \\
\text { implementação } \\
\text { de políticas } \\
\text { públicas, mas } \\
\text { não como } \\
\text { prestadoras de } \\
\text { serviço. }\end{array}$ & $\begin{array}{l}\text { Bastante } \\
\text { considerada, } \\
\text { tanto pelos } \\
\text { gestores } \\
\text { quanto pelos } \\
\text { movimentos } \\
\text { de mulheres, } \\
\text { que propõem } \\
\text { agendas } \\
\text { específicas. }\end{array}$ \\
\hline $\begin{array}{l}\text { Palmeira } \\
\text { das } \\
\text { Missões } \\
\text { - RS }\end{array}$ & $\begin{array}{l}\text { Baixa. O que } \\
\text { acontece é } \\
\text { o trabalho } \\
\text { conjunto do } \\
\text { CREAS e o } \\
\text { Judiciário, sem } \\
\text { a supervisão } \\
\text { de nenhuma } \\
\text { secretaria. }\end{array}$ & $\begin{array}{l}\text { Baixa. Estado } \\
\text { tem pouco } \\
\text { conhecimento } \\
\text { sobre o que } \\
\text { acontece nos } \\
\text { municípios, } \\
\text { apesar de, na } \\
\text { gestão anterior, } \\
\text { haver uma } \\
\text { orientação } \\
\text { para ajudar } \\
\text { a espalhar } \\
\text { as políticas } \\
\text { públicas. }\end{array}$ & $\begin{array}{l}\text { Judiciário } \\
\text { produzindo } \\
\text { política pública } \\
\text { junto com } \\
\text { burocratas de } \\
\text { nível de rua. } \\
\text { Organizações } \\
\text { da sociedade } \\
\text { civil promovem } \\
\text { ações com } \\
\text { o apoio da } \\
\text { Prefeitura. }\end{array}$ & $\begin{array}{l}\text { Algumas } \\
\text { gestoras e } \\
\text { burocratas de } \\
\text { nível de rua } \\
\text { consideram } \\
\text { o contexto } \\
\text { territorial na } \\
\text { leitura do } \\
\text { problema, mas } \\
\text { o diagnóstico } \\
\text { não gera } \\
\text { respostas } \\
\text { específicas. }\end{array}$ \\
\hline
\end{tabular}

Fonte: Elaborada pela autora

A primeira dimensão mostra-se determinante para que as políticas públicas sejam de fato implementadas, uma vez que o estabelecimento de uma rede de atendimento às mulheres em situação de violência depende da articulação entre secretarias, como saúde, educação, assistência social e o OPM. A participação do OPM na articulação e coordenação dessa rede faz a diferença no caso de Afogados da Ingazeira - PE, enquanto em Palmeira das Missões - RS, onde o OPM tem participação mínima, falta articulação. 
A dimensão da integração vertical também se mostrou determinante para os casos pesquisados. Por se tratarem de municípios com poucos recursos orçamentários, humanos e até técnicos - em comparação com outros de maior porte, a colaboração das secretarias de políticas para mulheres dos governos estaduais e federal impacta diretamente a capacidade de implementação das políticas públicas de enfrentamento à violência contra mulheres. A interação com a SPM do governo federal é praticamente nula, mas com os OPMs dos respectivos governos estaduais é radicalmente distinta. Enquanto a Secretaria da Mulher do governo do Pernambuco é uma referência técnica para a gestora do OPM de Afogados de Ingazeira - PE, além de o Estado assumir a gestão de várias políticas nos eixos de Proteção e Justiça; o Departamento de Políticas para Mulheres do governo do Rio Grande do Sul não consegue nem prover nem induzir políticas públicas em Palmeira das Missões - RS, mas aparece para as gestoras do município como um órgão apoiador de suas atividades.

A terceira dimensão, de coprodução de políticas públicas, aparece de forma pouco pronunciada nos dois casos estudados. Em Afogados da Ingazeira - PE, há intensa participação da sociedade civil na formulação e implementação das políticas públicas, mas as funções de provisão de serviços de atendimento às mulheres em situação de violência são assumidas pela Prefeitura, com coordenação do OPM. Já em Palmeira das Missões - RS, as organizações da sociedade civil promovem ações que são apoiadas pela Prefeitura, mas as funções do OPM, do Conselho Municipal de Direitos da Mulher e da sociedade civil não são claramente separadas, o que dificulta a identificação de processos participativos. No entanto, a cidade conta com um caso de coprodução entre o Poder Judiciário e a burocracia de nível de rua da Assistência Social, conforme descrito mais adiante.

A última dimensão diz respeito à consideração das questões territoriais nos arranjos de implementação. Em dois territórios tão distintos, foi possível identificar desafios muito diferentes no enfrentamento à violência de gênero, bastante discutidos por todas as gestoras e gestores entrevistados. No primeiro caso, no entanto, a interpretação da dimensão territorial é traduzida em especificações para as políticas públicas implementadas. Já no segundo caso, a leitura do território não gera respostas específicas, principalmente porque as políticas públicas de enfrentamento à violência contra mulheres do município são muito incipientes.

\section{O papel dos governos estaduais}

De acordo com a Política Nacional de Enfrentamento à Violência Contra as Mulheres, compete aos governos estaduais: "criação/reaparelhamento de delegacias especializadas no atendimento à mulher, defensorias especializadas, 
juizado especializado de violência doméstica e familiar contra a mulher; mutirão de assistência jurídica integral às mulheres em situação de prisão; capacitações e campanhas estaduais" (CARDOSO, 2009).

Além do que pode ser provido diretamente pelos estados, os OPMs estaduais também têm funções fundamentais na gestão do PNEVCM, como articular ações nos municípios, com apoio do governo federal, e monitorar as políticas públicas em andamento.

Ambos os estados pesquisados dispunham de secretarias de políticas para mulheres. Entretanto, no Rio Grande do Sul, ela foi rebaixada a um departamento dentro da Secretaria de Justiça e Direitos Humanos no primeiro mês de mandato da atual gestão Sartori (PMDB), em janeiro de 2015 - que viria a ser fundida com outras secretarias no mês seguinte à pesquisa, tornando-se a Secretaria de Desenvolvimento Social, Trabalho, Justiça e Direitos Humanos.

As diferenças entre as estruturas institucionais de políticas para mulheres nos dois estados ajudam a compreender o impacto da agência dos atores estaduais sobre essas políticas. Um OPM estadual fortalecido - com orçamento, equipe técnica e aval político - pode induzir municípios de toda a unidade federativa a implementar políticas para mulheres. Especialmente se a capilarização das políticas públicas para mulheres for uma diretriz das ações do órgão, e se houver gestoras especialmente destacadas para essa função.

Trata-se do caso do governo do Pernambuco, cuja atuação indutora impacta o trabalho da gestora do OPM de Afogados da Ingazeira - PE. Ela chegou a afirmar que sempre que tinha dúvida, procurava "o estado". Essa proximidade entre gestora municipal e estado também é fortalecida pelo fato de a Secretaria da Mulher do governo estadual destacar coordenadoras para acompanhar os trabalhos em cada território.

Outra função importante do OPM estadual é não só criar uma agenda própria e induzir a sua implementação junto aos municípios, mas também acompanhar o que tem sido feito dentro da temática. Nos casos de municípios de pequeno porte, que em geral têm orçamento e capacidades institucionais menores, esse acompanhamento auxilia na redução das discrepâncias regionais. Na comparação com Pernambuco, as gestoras do Rio Grande do Sul mostraram mais dificuldade em traçar um panorama territorial das políticas públicas implementadas.

O OPM estadual se distingue da Secretaria de Políticas para Mulheres do governo federal por conseguir acessar todos os municípios do seu estado, e é diferente do OPM municipal por contar com um corpo técnico mais robusto e maior acesso a recursos. Por isso, pode fazer o elo entre a agenda construída nacionalmente, os recursos federais e os municípios, em toda a sua diversidade. A atuação de OPMs 
municipais, por si só, não é suficiente para conseguir articular políticas públicas de enfrentamento à violência contra mulheres nos territórios - é preciso apoio dos governos estaduais para viabilizar as ações e, além disso, que as políticas de competência estadual estejam articuladas com a agenda local.

As experiências do Pernambuco e do Rio Grande do Sul mostram que a atuação intensiva da secretaria de políticas para mulheres de cada estado também pode impactar positivamente na consolidação dessas políticas públicas no âmbito municipal, reforçando a atuação dos OPMs municipais. A capacitação técnica das gestoras ${ }^{4}$ desses últimos, por exemplo, contribui para que prefeituras consigam acessar recursos e formular políticas públicas mais alinhadas à agenda nacional de políticas para mulheres - diminuindo a heterogeneidade das ações pelo território. Oferecer linhas de financiamento, doações e conveniamento são outras maneiras de os governos estaduais induzirem municípios a implementar as políticas.

Quando se trata de enfrentamento à violência contra mulheres, os governos estaduais têm a competência sobre as políticas de segurança pública, uma vez que comandam as polícias militar e civil. Caberia aos estados, portanto, monitorar dos casos de violência contra mulheres. Como eles não são obrigados a discriminar as motivações de gênero nos seus registros públicos de violência, é muito difícil acompanhar a evolução dos casos de forma homogênea.

No entanto, quando o enfrentamento à violência de gênero está na pauta, o governo estadual pode, além de monitorar os casos, assumir a frente na capacitação e sensibilização das forças de segurança sobre o tema e equipar os batalhões e delegacias com estrutura própria para o atendimento especializado de mulheres. Algumas prefeituras (como a de Afogados de Ingazeira - PE) realizam convênios com as polícias civil e militar de suas regiões para adequar o atendimento às demandas de enfrentamento à violência contra mulheres. No entanto, como nem todas as prefeituras têm capacidade técnica para assumir essa função, a atuação proativa dos governos estaduais garantiria que o atendimento à mulher em situação de violência pelas forças de segurança fosse adequado em todo o território das respectivas unidades federativas.

\section{Faz diferença existir um Organismo Municipal de Políticas para Mulheres?}

Ambos os municípios estudados dispunham de Coordenadorias de Políticas para Mulheres e Conselho Municipal dos Direitos da Mulher. Entretanto, a simples existência dessas estruturas não determina a implementação de políticas públicas.

\footnotetext{
${ }^{4}$ Escreve-se gestoras como forma de marcar a predominância de mulheres na direção de OPMs.
} 
Tanto em Afogados da Ingazeira - PE quanto em Palmeira das Missões - RS a agenda de políticas para mulheres é pautada pela própria sociedade civil que, com suas estratégias de ocupação dos espaços, ao longo dos últimos 15 anos vêm persuadindo os líderes políticos (em sua maioria, homens) locais a olhar para essa questão. Ambas as gestoras de OPM entrevistadas passaram pela sociedade civil e hoje exercem suas funções públicas de maneira bastante próxima aos prefeitos de suas cidades. Observa-se, no entanto, que os resultados produzidos em termos de políticas públicas são diametralmente opostos.

Em Afogados da Ingazeira-PE, o OPM, em pouco mais de dois anos de existência, é reconhecido por todas as atrizes e atores políticos entrevistados como estrutura essencial para alinhavar as políticas públicas do município. Por exemplo, organizando o fluxo de atendimento às mulheres em situação de violência e acompanhando políticas promovidas por outras secretarias nos eixos de prevenção, tratamento e responsabilização.

Já o OPM de Palmeira das Missões - RS, com praticamente o mesmo tempo de existência, não é reconhecido pelas pessoas entrevistadas pelas políticas públicas implementadas. A própria gestora municipal do OPM tinha dificuldade em listar o que foi feito - para além da organização de eventos e alguns atendimentos. Observou-se que a sociedade civil organizada adquiriu um status de influência que a tornou importante para o jogo político local, mas não conseguiu desenvolver uma agenda de ações robustas o suficiente para ganhar corpo depois da criação do OPM. Assim, o que existe no município não são políticas públicas para mulheres, e sim um apanhado de ações sem um fio condutor, com baixo impacto sobre as demandas de enfrentamento à violência contra mulheres.

Os dois casos contrastados mostram que a ação dos indivíduos e as trajetórias políticas das pessoas que assumem o comando de organismos como os OPMs importam. A instalação de uma coordenadoria da mulher não basta, portanto, para institucionalizar as políticas para mulheres dentro de uma gestão. A fundamentação técnica da agenda e a capacidade técnica e política das pessoas escaladas para gerílo se mostraram fatores primordiais. Isso acende uma luz para os OPMs estaduais que buscam fortalecer as políticas públicas nos municípios - capacitar tecnicamente as gestoras dos organismos municipais pode fazer toda a diferença.

O exemplo de Afogados da Ingazeira - PE ajuda também a compreender porque um OPM contribui para consolidar essas políticas em municípios de pequeno porte, de acordo com o que atestam Godinho (2004) e Alvarez (2004). A gestora do OPM e sua equipe são as pessoas da administração designadas para formular e implementar políticas próprias, mas também têm a função de "transversalizar" a perspectiva de gênero, articulando essa agenda com outras secretarias e órgãos públicos. Em Palmeira das Missões - RS, apesar de as políticas públicas para mulheres ainda não 
serem desenvolvidas no município, a criação do OPM ajudou a fortalecer o tema na agenda local de outros órgãos e do Poder Judiciário.

Em municípios pequenos, os próprios indivíduos conseguem acompanhar e articular a transversalidade, através do diálogo tête-à-tête com os demais atores políticos. A existência de estruturas mais formais de interlocução, entretanto, também pode auxiliar nesse processo, como em Afogados da Ingazeira - PE.

Outro reconhecimento da atuação positiva do OPM em Afogados da Ingazeira - PE vem da sociedade civil. As mulheres que compõem os movimentos locais destacam como, após a criação do organismo, as "pontas estão menos soltas". Reconhecem no OPM um elemento de fortalecimento da agenda de políticas para mulheres, e agregador entre os movimentos da sociedade civil e o poder público. Essa proximidade do organismo com a sociedade civil organizada (não só as representantes que compõem o Conselho Municipal de Direitos da Mulher) mostrase importante para promover pressão política localmente.

\section{Como multiplicar e manter equipamentos de abrigamento e Centros de Referência?}

A demanda por mais Casas-Abrigo, Casas de Passagem e Centros de Referência de Atendimento à Mulher é bastante vocalizada por movimentos nas discussões sobre políticas públicas de enfrentamento à violência contra mulheres (PRADO; SANEMATSU, 2017). A realidade de municípios de pequeno porte, entretanto, revela obstáculos tão grandes para a instalação desses tipos de equipamento, que exigem a intervenção dos governos estaduais.

Foi observado nos dois municípios que a justificativa de falta de recursos não é apenas uma saída retórica. Os próprios OPMs municipais não contavam com mais de duas pessoas em seus quadros e apenas um deles (Palmeira das Missões - RS) tem sede própria. Diante desse quadro, é controverso demandar às prefeituras a instalação de Centros de Referência ou Casas-Abrigo.

Quando se fala em abrigamento de mulheres em situação de violência, as pessoas entrevistadas são unânimes em destacar que se trata de "última opção" e que, no contexto de uma cidade pequena, só faz sentido abrigar a mulher fora da cidade ou do próprio estado - a depender da gravidade das ameaças de violência. Por esse motivo, os abrigamentos acionados pelas equipes de atendimento em municípios pequenos são viabilizados pela intermediação dos governos estaduais do Pernambuco e Rio Grande do Sul, que buscam vagas em casas de outros municípios.

Dessa forma, ao contrário do contexto urbano metropolitano, pautar prefeituras para a construção de equipamentos próprios de abrigamento pode não fazer tanto sentido, uma vez que dificilmente as mulheres em situação de violência se abrigam no próprio município. 
Uma solução encontrada no Rio Grande do Sul são os consórcios ${ }^{5}$ entre municípios para bancar a construção e manutenção de Casas de Passagem, o que permite que até municípios pequenos colaborem com sua implantação.

Já no Pernambuco, a própria Secretaria da Mulher do governo estadual se responsabiliza pela construção e administração dos equipamentos de abrigamento. O que desonera os municípios da função e permite uma padronização do atendimento e melhor distribuição territorial dos recursos. Uma vez que a secretaria já monitora os casos de violência registrados pelas polícias, a "estadualização" facilita o acompanhamento das mulheres em situação de violência que são deslocadas para outros municípios.

Os Centros de Referência de Atendimento à Mulher (CRAMs) são mencionados por muitas gestoras entrevistadas como equipamentos ideais para realizar o atendimento especializado às mulheres, por contar com equipe técnica destinada exclusivamente a conectar as mulheres às políticas públicas focalizadas. Em situações de violência, os CRAMs garantem apoio psicossocial à mulher, aumentando a efetividade das denúncias e desonerando outras equipes de atendimento.

Em Afogados da Ingazeira - PE, a gestora municipal do OPM destacou que a proposta de construir um CRAM já foi levada algumas vezes à Prefeitura, que sempre alega que os custos de manutenção de um equipamento próprio são muito altos.

$\mathrm{Na}$ ausência de um CRAM, o principal equipamento que faz o atendimento às mulheres em situação de violência é o Centro de Referência Especializado em Assistência Social (CREAS), cujos custos são apoiados pelo Sistema Único de Assistência Social (SUAS). Em Afogados da Ingazeira - PE, as mulheres organizadas em movimentos da sociedade civil e a própria gestora do OPM também apoiam o atendimento e orientação de mulheres em situação de violência. Já em Palmeira das Missões - RS, quem dá esse auxílio é a assistente social do Fórum da cidade.

\section{A necessidade de fortalecer a Assistência Social}

Depois da reestruturação das políticas públicas de assistência social e da criação do Sistema Único de Assistência Social, é possível encontrar em 99,9\% dos municípios brasileiros uma secretaria municipal de Assistência Social ${ }^{6}$ e ao menos um equipamento especializado como os Centros de Referência em Assistência Social

\footnotetext{
${ }^{5}$ Conforme estipulado pela normatização do Pacto Nacional pelo Enfrentamento à Violência Contra as Mulheres a respeito das possibilidades de atuação dos municípios: “c. Participar da Câmara Técnica de Gestão Estadual; d. Promover a constituição e o fortalecimento da rede de atendimento à mulher em situação de violência, no âmbito municipal e/ou regional, por meio de consórcios públicos (quando couber); [...]" (BRASIL, 2010).

${ }^{6}$ Suplemento especial sobre Assistência Social da Munic 2013, IBGE.
} 
$(\text { CRAS })^{7}$. Além disso, hoje 64,4\% dos OPMs dos municípios brasileiros são vinculados a outras secretarias - em mais de $80 \%$ desses casos, à Assistência Social ${ }^{8}$. Ou seja, trata-se de um sistema cada vez mais capilarizado no território brasileiro, como o Sistema Único de Saúde (SUS) e o Sistema Nacional de Educação.

Na prática, nota-se que muitas vezes os atendimentos de mulheres e meninas em situação de violência são realizados pelas equipes especializadas dos CRAS e CREAS. Por lidarem com vários tipos de violação de direitos, como violência a crianças e adolescentes, pessoas idosas e com deficiência, por exemplo, esse atendimento à mulher não necessariamente segue as diretrizes estabelecidas pela Política Nacional de Enfrentamento à Violência Contra as Mulheres. Da mesma forma, não necessariamente nos CRAS e CREAS são realizados encaminhamentos às políticas focalizadas a mulheres em situação de violência, essenciais para quebrar o ciclo de agressões. Mas a atuação de gestoras de políticas para mulheres junto à coordenação desses equipamentos pode gerar impactos positivos, conforme constatado em campo.

Em ambos os municípios pesquisados, os CREAS exerciam papel fundamental no atendimento às mulheres. Em Afogados da Ingazeira - $P E$, a gestora municipal do OPM mantinha diálogo próximo com a coordenação do CREAS e com a Secretária de Assistência e Desenvolvimento Social. Dessa forma, ainda que não exista CRAM, o OPM monitora o atendimento às mulheres em situação de vulnerabilidade do município.

Já em Palmeira das Missões - RS, a equipe especializada do CREAS acompanha as mulheres em situação de vulnerabilidade do município, uma vez que o OPM não assume essa função nem monitora os atendimentos realizados pela Assistência Social. Entretanto, por ter que lidar com todos os casos de violação de direitos em suas diversas variações, a equipe do CREAS não consegue focalizar as políticas públicas. A única garantia de qualidade no padrão desse atendimento é a própria formação dos membros da equipe, já que a assistente social do CREAS tem especialização em violência doméstica. $O$ alinhamento sobre os casos de violência e seus encaminhamentos acontecia diretamente com os operadores do Sistema de Justiça - relação que será tratada adiante.

As situações encontradas nesses municípios chamam a atenção para duas necessidades:

\footnotetext{
7 De acordo com os dados da Munic 2013, do IBGE, de 2009 para 2013, o número de CRAS passou de 5.499 em 4.032 municípios para 7.986 em 5.437 municípios.

${ }^{8}$ Munic 2013, IBGE
} 
- os profissionais de atenção psicossocial precisam estar preparados para o atendimento especializado de mulheres em situação de violência, principalmente se os equipamentos onde trabalham são a principal porta de entrada dessas pessoas nos municípios;

- o atendimento psicossocial demanda acompanhamento dos casos por parte das gestoras dos OPM municipais para garantir a focalização das políticas públicas às mulheres em situação de vulnerabilidade.

O fortalecimento dos serviços de assistência social se mostra, portanto, essencial para garantir o acesso de mulheres de municípios de pequeno porte às políticas públicas. É importante garantir tamanhos adequados às equipes, para evitar sobrecargas e possibilitar treinamentos para lidar com esses casos específicos. 0 que se traduz em mais recursos para a contratação de pessoal e na gestão do tempo desses profissionais.

Essa constatação pode levantar um dilema real vivido por gestores e gestoras de muitos municípios brasileiros. Diante dos recursos limitadíssimos para a contratação de pessoal, teriam que decidir entre contratar uma equipe especializada no atendimento às mulheres (para trabalhar em um CRAM, por exemplo), ou ampliar a equipe do CREAS já existente.

Nesta discussão, esse dilema, mesmo sendo real, não é central. Os resultados observados mostram que a Assistência Social, pela importância que ganhou nos últimos anos e por sua capilaridade, é uma área fundamental e precisa ser fortalecida para garantir a implementação de políticas públicas de enfrentamento à violência contra mulheres. O que, no entanto, não suplanta a necessidade de o município dispor de equipe destacada para desenhar estratégias de focalização das políticas públicas para mulheres, monitorar os acompanhamentos e pautar a qualidade do atendimento às mulheres em todos os serviços públicos municipais. Ainda que os atendimentos sejam realizados por profissionais da Assistência Social e não de um equipamento próprio do OPM, essa equipe especializada tem a função de garantir que as mulheres continuem a ser assistidas por políticas públicas que as permitam romper o ciclo da violência.

Especificamente para garantir o atendimento às mulheres em situação de vulnerabilidade em municípios de pequeno porte, vale pensar em como usar o próprio SUAS e seus programas, uma vez que as políticas públicas de assistência social já chegaram ao vocabulário dessas prefeituras. O custeio de estruturas e equipes para os CREAS, em conjunto com a formação de quadros técnicos para a coordenação de políticas para mulheres, podem ser maneiras de fazer os serviços mínimos (em atenção psicossocial e acesso a direitos, principalmente) chegarem às mulheres desses municípios. 


\section{Territorialização e a adaptação às dinâmicas locais}

Outro desafio encarado pelas gestoras de políticas públicas para mulheres é conseguir estender o impacto e o alcance de suas ações por todo o território, ao mesmo tempo em que adaptam as políticas às dinâmicas culturais e socioeconômicas de cada local.

Em Palmeira das Missões - RS, segundo as pessoas entrevistadas destacaram como a estrutura familiar "tradicional" - biparental, monogâmica e heterossexual - compõe o contexto socioeconômico da região. Muitas das mulheres que sofrem violência doméstica passam por essa situação por anos a fio até tomarem a coragem de denunciar.

Ainda de acordo com as pessoas entrevistadas, esse contexto dificulta a responsabilização dos casos de violência, porque grande parte das mulheres tende a desistir da denúncia no meio do processo judicial, por não querer se separar do agressor ou por perceber que ele pode ser responsabilizado criminalmente. $\mathrm{Na}$ análise dos próprios operadores da Justiça e burocratas de nível de rua entrevistados, esse cenário demandaria métodos alternativos de responsabilização (como a reabilitação dos próprios agressores) e serviços especializados de orientação e atendimento psicossocial dessas mulheres. No caso estudado, no entanto, seria necessário que a gestora municipal do OPM se amparasse nos diagnósticos da realidade local, realizados por esses operadores, para implementar políticas públicas que ampliem a efetividade da Lei Maria da Penha.

Em Afogados da Ingazeira - PE, o contato próximo entre o OPM e os movimentos de mulheres locais permite leituras mais detalhadas sobre o território. Em primeiro lugar, porque esses movimentos estão organizados em todo o território, inclusive nas comunidades rurais e quilombolas. Dessa forma, a gestora do OPM municipal conta com as lideranças desses movimentos para ajudarem a fazer "vigilância" sobre os casos de violência que acontecem no território do município. Os casos identificados são notificados ou encaminhados ao OPM, ampliando o alcance dessas políticas públicas. Em segundo lugar, porque nos espaços e participação do município e da região, os movimentos se organizam em comissões para formular, sugerir e acompanhar políticas públicas de agendas específicas, como de saúde e sexualidade de mulheres negras e inclusão produtiva de mulheres rurais. Os municípios da região do Pajeú constituem um consórcio intermunicipal, onde foi criado também um Conselho Intermunicipal de Políticas Públicas para Mulheres. Nesse conselho, movimentos locais e OPMs desses municípios trocam experiências e formulam agendas conjuntas. 


\section{Onde está a coprodução de políticas públicas?}

A parceria com atores não-estatais na provisão de serviços às mulheres em situação de violência é bastante comum no Brasil, inclusive entre os serviços conveniados pelos OPMs municipais. Nos municípios estudados, porém, a principal função das organizações da sociedade civil é pautar a agenda local com as demandas por políticas públicas para mulheres, especialmente de enfrentamento à violência de gênero.

Em Afogados da Ingazeira - PE, a gestora do OPM foi indicada pelos próprios movimentos de mulheres da região. Não há provisão de serviços públicos realizada pelas organizações em conveniamento com a Prefeitura, mas o OPM aciona-as para apoiar as iniciativas da Prefeitura - como campanhas, seminários e formações. Após a criação dos OPMs, os movimentos de mulheres assumiram o Conselho Municipal de Direitos da Mulher como espaço oficial de participação, onde as agendas comuns são construídas.

Em Palmeira das Missões - RS, a gestora do OPM também foi indicada pelo movimento de mulheres da região. No entanto, a Prefeitura não tem uma agenda própria de políticas públicas para mulheres, e acaba se apropriando das ações realizadas pela sociedade civil. Ou seja, não há provisão de serviços em parceria com a sociedade civil, mas ela realiza atividades com apoio institucional e financeiro da Prefeitura, que depois são listadas como ações "oficiais". Esse é um dos reflexos da mistura de competências entre poder público e sociedade civil que se passa no município.

Se a Prefeitura e o OPM municipal conseguem desenvolver as relações com as organizações da sociedade civil e respeitar sua independência de atuação, é possível desenvolver a legitimidade da agenda de políticas públicas para mulheres e ampliar o seu alcance. Como os OPMs são novos e os municípios não têm histórico de ações dentro dessa temática, a Prefeitura pode aprender com a sociedade civil organizada sobre o que deve ser feito e as melhores práticas para se conectar com as mulheres do território.

\section{A atuação proativa do Sistema de Justiça}

A atuação forte do Sistema de Justiça na implementação das políticas públicas de enfrentamento à violência contra mulheres é esperada, uma vez que elas se tratam, grosso modo, da efetivação da Lei Maria da Penha.

As competências dos municípios centram-se nos eixos proteção e promoção da cidadania. Já a função do Judiciário seria focada na responsabilização das pessoas 
agressoras. Na prática, o que se verifica é que as competências se mesclam, inclusive para integrar as ações. Quando uma das partes não cumpre totalmente com as suas funções dentro dessas políticas públicas, outros atores podem "estender" a cobertura de suas funções para atender à demanda.

Os dois casos contrastados, mais uma vez, mostram padrões muito distintos de atuação do Sistema de Justiça e das forças de segurança pública. Em Afogados da Ingazeira - PE, a Polícia Militar e o Ministério Público são citados como "parceiros" no enfrentamento à violência contra mulheres. O chefe do Batalhão e o promotor estão em constante diálogo com a gestora do OPM municipal para alinhar procedimentos sobre o atendimento às mulheres e a fiscalização das medidas protetivas. A gestora se responsabiliza, portanto, em verificar se esses atores estão cumprindo seus papéis dentro da política.

Já em Palmeira das Missões - RS, a gestora do OPM municipal acompanha pouco a atuação do Judiciário ou mesmo das forças de segurança. O alinhamento sobre o atendimento às mulheres em situação de violência acontece, então, de maneira informal entre os operadores da Justiça e a burocracia de nível de rua. São os mesmos atores e atrizes que acabam, pelas funções do ofício, monitorando, ainda que de maneira simplificada, os casos de violência. Diante dos problemas que aparecem no dia a dia do atendimento e da inação do Executivo, o Poder Judiciário local (na figura do juiz coordenador do fórum e da assistente social), em parceria com burocratas de nível de rua do CREAS, experimenta ações relacionadas aos eixos de competência municipal, como a condução de dois grupos de apoio para mulheres em situação de violência. 0 grupo planeja, inclusive, usar as ações já em curso para tentar pautar o Executivo e inspirar políticas públicas. Outra iniciativa mapeada é a tentativa de trazer os gestores municipais à mesma mesa para discutir a estruturação da Rede de Atendimento à Mulher em Situação de Violência.

Nesse município, a atuação proativa do Judiciário e de alguns burocratas de nível de rua configura uma das poucas possibilidades de sobrevivência da Lei Maria da Penha. O risco dessa "gestão de improviso" da política é a insustentabilidade: sem uma coordenação a partir do primeiro escalão da gestão municipal, as garantias de acesso a direitos por parte das mulheres em situação de violência ficam nas mãos de alguns burocratas de nível de rua que se identificam com a causa o suficiente para prover o atendimento e outras iniciativas. Da mesma forma, o exemplo positivo de Palmeira das Missões - RS mostra a importância de o Sistema de Justiça sensibilizar seus operadores para as questões de gênero e prepará-los para os desafios imbricados na efetivação de uma legislação tão cheia de complexidades quanto a Lei Maria da Penha. 


\section{Considerações finais}

O presente trabalho visa contribuir para a discussão sobre a implementação de políticas públicas de enfrentamento à violência contra mulheres em diferentes contextos. Buscou-se, portanto, compreender como essas políticas públicas podem ser implementadas, observando as premissas estabelecidas pelo Pacto Nacional pelo Enfrentamento à Violência Contra Mulheres, em municípios de pequeno porte - realidade pouco analisada no âmbito de políticas públicas de gênero.

Os resultados apontam para algumas conclusões. A primeira diz respeito à atuação dos OPMs nos municípios, organismos que se mostram essenciais para coordenar políticas públicas. A trajetória política e as capacidades técnicas das pessoas que assumem a coordenação dos OPMs - e, em municípios pequenos, geralmente trabalham sozinhas - importa tanto quanto a própria existência dessas estruturas. Elas são responsáveis, pois, por levar a perspectiva de gênero a todos as atrizes e atores atuantes no território, principalmente aos outros setores do Poder Executivo; e articular uma rede de enfrentamento à violência contra mulheres no território. Nesse sentido, as ferramentas de monitoramento e de gestão intersetorial podem fazer a diferença.

É preciso formar uma agenda consonante com os princípios da Política Nacional de Enfrentamento à Violência Contra as Mulheres, e nesse sentido, os OPMs dos governos estaduais devem dar subsídios técnicos, acompanhar o trabalho dos municípios e promover a temática de gênero. Isso leva à segunda conclusão: a atuação dos governos estaduais é fundamental para municípios de pequeno porte, que trabalham com orçamentos curtos e têm menores capacidades institucionais. Eles dependem de "intermediários" para conseguir implementar políticas de âmbito nacional - especialmente quando se trata de uma agenda emergente. Os governos estaduais, além de fazerem a ligação entre os recursos federais e os governos municipais, são os principais responsáveis pela política de Segurança Pública, eixo fundamental do enfrentamento à violência contra mulheres. Portanto, ainda que um município disponha de gestoras e gestores comprometidos com a temática e tente implementar essas políticas, o alcance de suas ações é limitado quando o governo estadual não cumpre suas funções.

Ambos os casos não dispunham de equipamentos especializados de atendimento psicossocial à mulher em situação de violência, mas conseguiam fornecer esse serviço por meio dos equipamentos de Assistência Social. O que remete ao terceiro ponto, sobre a dificuldade de municípios de pequeno porte manterem equipamentos especializados. Ainda que haja apoio técnico e financiamento 
para a sua construção, a manutenção dos mesmos traz custos incompatíveis com a realidade dessas Prefeituras. As soluções apontadas são a formação de consórcios ou a "estadualização" da gestão de equipamentos especializados. Outra questão relacionada é a necessidade de fortalecer a Assistência Social e vincular o atendimento às mulheres em situação de violência aos programas federais financiados pelo SUAS. A participação ativa desse setor na rede de atendimento, por sua vez, só reforça a importância dos mecanismos de gestão intersetorial das políticas públicas no nível municipal.

A quarta conclusão é que a adaptação das políticas públicas às dinâmicas do território está intrinsecamente ligada à participação da sociedade civil na sua produção. Em municípios pequenos, as organizações temáticas da sociedade civil têm força para pautar a agenda local, de forma a conferir legitimidade às políticas públicas de enfrentamento à violência contra mulheres; e também para estender o alcance dessas políticas. A coprodução com a sociedade civil enriquece a leitura dos gestores públicos locais sobre as demandas específicas do território e da diversidade de mulheres, adaptando as iniciativas e aumentando sua efetividade. Além disso, trata-se de uma agenda recente, na qual as organizações da sociedade civil detêm maior conhecimento e acúmulo histórico que o poder público.

Destaca-se como última conclusão que a proatividade do Sistema de Justiça nos municípios de pequeno porte pode impulsionar ações do Executivo e amparar as mulheres que buscam ajuda do Estado quando falta atuação da Prefeitura. Assim como na relação entre governos municipais e estaduais, quando uma das partes não cumpre totalmente com as suas funções dentro dessas políticas públicas, a outra pode flexibilizar as suas funções para atender às demandas emergentes. O que, no entanto, não é suficiente diante da complexidade do problema enfrentado.

Por fim, é importante ressaltar que a pesquisa esbarrou nas dificuldades em encontrar referências a municípios de pequeno porte. A maior parte das gestoras entrevistadas, quando solicitadas a indicar um município de até 50 mil habitantes que fosse referência na implementação das políticas públicas estudadas, faziam referências a municípios maiores e de regiões metropolitanas, explicitando a invisibilidade dessa categoria até mesmo entre as gestoras responsáveis por capilarizar as políticas para mulheres no território. Essa dificuldade, por si só, aponta para a necessidade de ampliar a atenção sobre esse universo, que segundo o IBGE, corresponde a $88,24 \%$ dos municípios brasileiros, onde reside $32,1 \%$ da população. 


\section{Referências Bibliográficas}

Alvarez, S. Falas do Estado ou o estado das falas sobre as mulheres nas administrações democrático-populares. In: GodinHo, T.; SILVEIRA, M. L. da (Orgs.). Políticas públicas e igualdade de gênero. São Paulo: Prefeitura do Município de São Paulo, Coordenadoria Especial da Mulher, 2004, p. 103-123.

ARRetche, M. Relações Federativas nas Políticas Sociais. Educ. Soc., Campinas, v. 23, n. 80 , set/2002, p. 25-48.

BANDEIRA, L. Brasil: Fortalecimento da Secretaria Especial de Políticas para as Mulheres para avançar na transversalização da perspectiva de gênero nas 291 políticas públicas (Documento de la Reunión de Expertos "Políticas y programas de superación de la pobreza desde la perspectiva de la gobernabilidad democrática y el género"). Quito: CEPAL/Unidad Mujer y Desarrollo, 2005.

BARRETT, S. Implementation Studies: Time for a Revival? Personal Reflections on 20 Years of Implementation Studies. Public Administration, Blackwell Publishing: Oxford, v.82, n. 2, 2004, p. 249-262.

Batista, N.C.S.; Bernardes, J.; Menegon, V.S.M. Conversas no cotidiano: um dedo de prosa na pesquisa. In: SPINK, M.J.; BRIGAGÃo, J.; Nascimento, V.; CORDEIRO, M. (Orgs.). A produção de informação na pesquisa social: compartilhando ferramentas organizadoras. Rio de Janeiro: Centro Edelstein de Pesquisas Sociais, 2014 (publicação virtual).

BICHIR, R. Mecanismos federais de coordenação de políticas sociais e capacidades institucionais locais: o caso do Programa Bolsa Família. [Tese] Universidade Estadual do Rio de Janeiro. Rio de Janeiro, 2011.

BRASIL. Lei n. 10.778/03. Presidência da República. Brasília, 2003.

Política Nacional de enfrentamento à violência contra as Mulheres. Secretaria Nacional de Enfrentamento à Violência contra as Mulheres, Secretaria de Políticas para as Mulheres - Presidência da República. Brasília, 2011.

Pacto Nacional pelo enfrentamento à violência contra as Mulheres. Secretaria Nacional de Enfrentamento à Violência contra as Mulheres, Secretaria de Políticas para as Mulheres - Presidência da República. Brasília, 2010.

Bresser-PereirA, L. C. Uma reforma gerencial da Administração Pública no Brasil, Revista do Serviço Público/Fundação Escola Nacional de Administração Pública, v. 1, n. 1, nov/1937 - Ano. 49, n.1 jan-mar/1998. Brasília: ENAP, 1937.

CALAZANS, M.; CORTÉs, I. (2011), O processo de criação, aprovação e implementação da Lei Maria da Penha. In: CAMPOS, C. H. C. (Org.). Brasil. Lei Maria da Penha comentada em uma perspectiva jurídico-feminista. Rio de Janeiro: Lumen Yuris, 2011, p. 39-63.

CARDoso, J. C. (Org.) Brasil em desenvolvimento: Estado, planejamento e políticas públicas / Instituto de Pesquisa Econômica Aplicada. Brasília: IPEA, 2009. 3 v. : gráfs., tabs. (Brasil: o estado de uma nação). 
CARneIro, S. Mulheres em movimento. Revista Estudos Avançados, São Paulo, v. 17, n. 49, p. 117-132, 2003. Disponível em: <http://www.revistas.usp.br/eav/article/ view/9948/11520>, 2017

CoRdeIRo, R.M., BRASILINo, J., CARDONA, M.G. Observação no cotidiano: um modo de fazer pesquisa em psicologia social. In: SPINK, M. J., BRIGAGÃo, J., Nascimento, V. e CORDEIRo, Mariana. (Org.) A produção de informação na pesquisa social: compartilhando ferramentas organizadoras. - 1.ed. - Rio de Janeiro: Centro Edelstein de Pesquisas Sociais, 2014

Cunill GraU, N., 2005. La Intersectorialidad en el Gobierno y Gestión de la Política Social. In: X Congreso Internacional del CLAD. Santiago.

FARAH, M. F. S. Gênero e Políticas Públicas: iniciativas de governos subnacionais no Brasil. Relatório n. 10/2002. Publicações seriadas. São Paulo: Escola de Administração de Empresas de São Paulo, Fundação Getúlio Vargas, Núcleo de Pesquisas e Publicações. Série Relatórios de Pesquisa, 2002.

FARIA, C. A. P. Idéias, Conhecimento e Políticas Públicas: um inventário sucinto das principais vertentes analíticas recentes. Revista Brasileira de Ciências Sociais, Vol. 18, no. 51, Fevereiro de 2003.

GodINHO, T. Construir a igualdade combatendo a discriminação. In: GodINHO, T. e SilveirA, M. L. da (orgs.). Políticas públicas e igualdade de gênero. São Paulo: Prefeitura do Município de São Paulo, Coordenadoria Especial da Mulher, 2004, p.55-64.

Gomide, A. A.; PIRES, R. R. C. (eds) Capacidades Estatais e Democracia: arranjos institucionais de políticas públicas. Brasília, IPEA, 2014.

Burocracia, democracia e políticas públicas: arranjos institucionais de políticas de desenvolvimento. Texto para Discussão 1940, Ipea, 2012.

HILL, M.; HUPE, P. (2002) Implementing Public Policy: Governance in Theory and in Practice. London. Sage.

HUPE, P.L. (1993a) 'The politics of implementation: Individual, organisational and political co production in social services delivery', in M. Hill (ed.), New Agendas in the Study of the Policy Process. Hemel Hempstead: Harvester Wheatsheaf. pp. 130-51.

IBGE, 2014. Pesquisa de Informações Básicas Municipais: Perfil dos Municípios Brasileiros 2013. Rio de Janeiro: 282 p.

INOJOSA, R.M., 1998. Intersetorialidade e um novo paradigma organizacional. Revista de Administração Pública, 32(2), pp.35-48.

IPEA, 2011. Retrato das desigualdades de gênero e raça / Instituto de Pesquisa Econômica Aplicada [et al.]. 4. ed. Brasília

LOTTA, Gabriela; FAVARETo, Arilson. Desafios da integração nos novos arranjos institucionais de políticas públicas no Brasil. Rev. Sociol. Polit., Curitiba, v.24, n. 57, p. 49-65, Mar. 2016.

LOTTA, G. S.; VAZ, J. C. Arranjos institucionais de políticas públicas: aprendizados a partir de casos de arranjos institucionais complexos no Brasil. Revista do Serviço Público. Brasília. 66 (2) 171-194, abr/jun de 2015. 
Macdowell SAntos, C. Da delegacia da mulher à Lei Maria da Penha: Lutas feministas e políticas públicas sobre violência contra mulheres no Brasil. Revista crítica de Ciências Sociais, n.o 89, 2010 (Exemplar: Estudos feministas e cidadania plena), págs. 153-170.

Martins, A. P. A. M.; CerqueirA, D. e Matos, M V. M. "A institucionalização das políticas públicas de enfrentamento à violência contra as mulheres no Brasil (versão preliminar)", Brasília: Nota Técnica do Instituto de Pesquisas Econômicas Aplicadas, n. 13,2015

Observatório Brasil da igualdade de Gênero. "Conselhos e Organismos", disponível em http://www.observatoriodegenero.gov.br/eixo/politicas-publicas/ conselhos-e-organismos. Acessado em 02 de março de 2017

OStRoM, E. (1996) Crossing the Great Divide: Coproduction, Synergy, and Development. World Development, 24:6 pp.1073-87.

PINTO, C. R. J. Mulher e Política no Brasil: Os impasses do feminismo, enquanto movimento social, face às regras do jogo da democracia representativa. Revista Estudos Feministas. Ano 2, 2a sem. p.256-270, 1994

Pitanguy, J. A questão de gênero no Brasil. CEPIA-Cidadania, Estudo, Pesquisa, Informação e Ação, 2003.

Movimento de Mulheres e Políticas de Gênero no Brasil. CEPIACidadania, Estudo, Pesquisa, Informação e Ação, 2002.

PRÁ, J.R.; EPPING, L. Cidadania e feminismo no reconhecimento dos direitos humanos das mulheres. Revista Estudos Feministas, Florianópolis, 20(1): 33-51, janeiro-abril/2012.

Prado, D., Sanematsu, M. Feminicídio: \#InvisibilidadeMata. Fundação Rosa Luxemburgo. Sao Paulo: Instituto Patrícia Galvão, 2017

PRESSMAN, J.; WILdAVSKY, A. (1984) Implementation: How Great Expectations in Washington are Dashed in Oakland. Berkeley: University of California, Los Angeles.

SOARES, V. Movimento feminista: Paradigmas e desafios. Revista Estudos Feministas, ano 2, 2 sem., Universidade Federal de Santa Catarina, 1994.

Políticas públicas para igualdade: papel do Estado e diretrizes. In: Godinho, T. e SilveIRA, M. L. da (orgs.). Políticas públicas e igualdade de gênero. São Paulo: Prefeitura do Município de São Paulo, Coordenadoria Especial da Mulher, 2004, p.113-126.

TOPS, P. E. W. M. (1999) "Co-productie als bestuursstijl: Ervaringen en vuirstregels”, Bestuurswetenschappen, 53 (3): 201-225

WAISENFILZ, J. Mapa da Violência 2015: Homicídio de mulheres no Brasil. Brasília: Flacso, 2015. Disponível em: <http://www.mapadaviolencia.org.br/pdf2015/ MapaViolencia_2015_mulheres.pdf>

\section{Ana Carolina Almeida Santos Nunes}

Pesquisadora e comunicadora, mestre em Políticas Públicas pela Universidade Federal do ABC (UFABC) e graduada em Jornalismo pela Universidade de São Paulo (USP). Contato: ananunes14@gmail.com 
